$$
\begin{aligned}
& \text { 지역주민 태도에 의한 수변공간 개발 형태 분석 }{ }^{\dagger} \\
& \text { - 여주시를 중심으로 - } \\
& \text { 유수진* · 석영선* · 최윤의* · 전진형** }
\end{aligned}
$$

*고려대학교 대학원 환경생태공학과 · **고려대학교 환경생태공학부

\title{
An Analysis of Waterfront Development Type based on Residents' Attitudes - Focused on Yeoju-Si -
}

\author{
You, Soo-Jin* $\cdot$ Seok, Young-Sun* $\cdot$ Choi, Yun Eui* $\cdot$ Chon, Jinhyung** \\ *Dept. of Environmental Science and Ecological Engineering, Graduate School, Korea University \\ ${ }^{* *}$ Division of Environmental Science and Ecological Engineering, Korea University
}

\begin{abstract}
The importance for local development, which residents' attitudes have reflected, is well known. Therefore, in order to formulate an approach for sustainable development, a study on sustainable waterfront development has become necessary. This study performed the first step analysis of Limits of Acceptable Change(LAC) System that considers the local residential attitude to make the analysis and standard for acceptable development type in the waterfront. This study used the characteristics of the residents, the social exchange theory, and the LAC System. This was done because it is useful to ensure that basic data can be used for the establishment of management objectives. Yeoju-Si was selected as the site for the investigation. A total of 240 surveys were obtained. Analyses were conducted to 1) determine the relationships between the residents' attitudes toward the waterfront development type and the acceptable development type and 2) to examine relationships between the residents' characteristics and the residents' attitudes toward the waterfront development. The results of this study are as follows: The development pertaining to the parameter 'nature education' arguably has the potential to generate substantial revenues for Yeoju-Si and could link the local development and conservation. This study concludes that the area of residence were closely correlated with the residents' attitudes.
\end{abstract}

Key Words: Social Exchange Theory, Limits of Acceptable Change(LAC), Area of Residence, Residents' Characteristics

$$
\text { 국문초록 }
$$

최근 몇 년간 수변공간 개발에 대한 관심이 증가하면서 지속가능한 지역균형 발전을 목표로 하는 지역개발 정책 및 사업이 증가하였다. 이러한 과정에서 생활환경 변화에 대한 지역문제가 발생하게 되었고, 지역주민태도를 반영한 개발

\footnotetext{
${ }^{\dagger}:$ 본 연구는 환경부 차세대 에코이노베이션기술개발사업(과제명: 습지생태계조성 및 자연생태 회복기술 개발, 과제번호: 416-111-010) 에 의하여 연구를 수행하였으며, 이에 감사드립니다.

Comesponding author: Jinhyung Chon, Division of Environmental Science and Ecological Engineering, Korea University, Seoul 136-713, Korea, Tel.: +82-2-3290-3048, E-mail: jchon@korea.ac.kr
} 
계획의 중요성이 부각되었다. 본 연구에서는 새로 조성된 수변공간에 대하여 허용 가능한 개발형태 분석 및 향후 개발 목표를 설정하기 위해, 사회교환이론을 바탕으로 지역주민 태도를 고려하여 LAC 시스템의 첫 번째 단계에 대한 분석을 실시하였다. 이를 위해 여주시 지역주민 240명을 대상으로 수변공간 개발에 대한 주민태도, 허용 가능한 수변공간 개발 형태, 주민특성을 설문하였다. 설문한 데이터에 대한 기술통계분석, 요인분석을 실시한 뒤, 수변공간 개발에 대한 주민태도 에 따른 허용 가능한 개발 형태를 알아보기 위해 다중회귀분석을 실시하였다. 다음으로 거주특성과 수변공간 개발에 대한 주민태도와의 차이를 알아보기 위해 기술통계분석, 요인분석, $T$-test, 일원분산분석(one-way ANOVA)를 실시하였다. 그 결과, 여주시 지역주민들이 허용하는 수변공간 개발 형태는 자연교육중심 개발 형태라는 것을 확인할 수 있었으며, 거주지역에 따라 수변공간 개발에 대한 형태에 차이가 나타나는 것을 확인할 수 있었다. 본 연구의 결과를 통해 수변공간의 개발 및 관리 목적을 설정하고, LAC 후속단계인 휴양자원 등급화의 적용범위에 대한 기준을 마련할 수 있었다.

주제어: 사회교환이론, 허용변화한계, 거주지역, 거주특성

\section{I. 서론}

수변공간은 시대의 특성과 문화에 따라 지속적으로 개발 되어왔으며, 1990년대 들어서 시민여가공간으로써 그 역할 이 확장되기 시작했다(Ministry of Culture Sports and Tourism, 2011). 수변공간은 지역차원에서 도시재생, 공공성 확보 등에 기여하였으며, 문화적 측면에서 수상레저, 야간경관 감상 등의 친수문화 및 생태체험 문화공간으로 범위를 확장하였다(Baek and Noh, 2006; Ministry of Culture Sports and Tourism, 2011). 또한 수변공간은 수면부와 육지가 교차하는 곳으로, 생태적 측 면에서 풍부한 생물자원을 보유하고 있기 때문에, 생태계 보호 및 친환경적인 공간 조성이 가능한 특성을 가지고 있다(Rural Development Administration, 2012). 최근에는 지역개발에 있어 지속가능한 지역균형발전을 목표로 하는 정책 중 수변공간을 대상으로 하는 사례가 증가하였으며, 관련 정책 및 사업들이 추진되고 있다. 하지만 수도권 교외지역에 위치한 수변공간의 경우, 그 동안 도시지역에서 수행되었던 다양한 선례들을 무 비판적으로 수용하였을 뿐, 지역주민의 태도와 허용한계선과 같은 의견 수렴이 미흡한 상태로 개발되고 있는 실정이다 (Park and Kim, 2011). 이와 같은 현상은 지역개발 및 정비계 획에 있어 관례상 하향식 접근방식으로 배치의 공정성 이용만 을 획일적으로 지향한 결과로 해석된다 $(\mathrm{Kim}, 2007)$. 또한 개 발로 인한 외부 방문객의 증가는 지역사회 충돌 및 지역발전 기회 감소, 주민혼란에 따른 삶의 질 저하와 같은 사회적 문제 를 발생시키고 있다(Ahn et al., 2002). 이에 대한 해결방안으 로 실제 지역주민들의 수요나 이용경향과 같은 의견수렴 과정 에 대한 필요성이 제기되었다(Kim, 2007). 특히 개발과 관련 된 주요 행위자, 즉 지역주민의 태도를 통해 지역의 환경 및 사회적 변화의 허용한계에 대한 검토는 모범적 사례로 활용 되었다(Kim, 2004; Jeong et al., 2007). 허용한계 검토를 위해 서는 허용변화한계(LAC: Limits of Acceptable Change) 시스 템을 도입할 수 있다. LAC는 지역의 이용객으로부터 변화하
는 환경을 고려하여 관리계획을 마련하기 위한 기준을 의미 한다(Jeong et al., 2007). LAC의 결정 과정은 첫째, 지역의 허용 가능한 개발형태 분석 및 개발목표 설정, 둘째, 첫 단계 에서 설정한 목적과 지역의 현황 간의 관계 분석, 셋째, 최적 의 대안 개발, 넷째, 평가 및 모니터링의 네 단계를 거친다 (Kim, 2003). 특히 LAC의 첫 번째 단계는 지역주민의 태도 와 의견이 반영되는 단계로, 후속 단계의 준거 틀이 되기 때 문에 신중하게 평가되어야 한다. 이에 본 연구에서는 과거 수 도권정비계획법상 자연보전권역으로 개발이 제한되다 규제완 화로 개발이 진행되기 시작한 여주시의 수변공간을 대상으로 지역주민 태도를 고려한 LAC 시스템의 첫 번째 단계를 분석 하였으며, 수변공간의 허용 가능한 개발형태 분석 및 LAC 후 속 단계의 개발목표 설정을 목적으로 하였다. 연구의 세부 목 표는 첫째, 지역주민의 어떠한 태도가 허용 가능한 개발 형태 에 영향을 미치는지를 파악하는 것이며, 둘째, 지역주민의 거 주특성에 따라 수변공간 개발에 대한 태도에 차이가 있는지 에 대해 검증해 보는 것이다. 본 연구를 통해 지역주민들이 생각하는 허용 가능한 수변공간 형태를 도출할 수 있으며, $\mathrm{LAC}$ 시스템의 후속단계에 대한 기초자료로 활용될 수 있을 것이다.

\section{II. 이론적 고찰}

\section{1. 수변공간 개발}

수변공간은 사람들의 생활지역에서 큰 강이나 바다, 호수 등 과 접해 있어 비옥한 토지가 형성되어 있으며, 인류의 문명 발 달과 함께 자연과 도시가 만나는 공간적 특징을 가짐으로써 사 람들 간의 교류와 소통이 일어나는 공간이다(Lee et al., 2012; Kim et al., 2013). 과거 우리나라의 하천은 기후특성 상, 갈수 기와 홍수기의 유량 편차가 심하기 때문에 이수, 치수기능 위주 로 개발되었다(Lim, 1998; Shim and Baek, 2000; 
Table 1. Use pattern of chronological waterfront

\begin{tabular}{|c|c|c|c|c|}
\hline Step & Age & Character & Life culture & Using pattern \\
\hline Passive use & $\begin{array}{l}\text { The Joseon } \\
\text { Dynasty period }\end{array}$ & $\begin{array}{l}\text { The feudal society on the } \\
\text { agricultural infrastructures }\end{array}$ & $\begin{array}{l}\text { - Culture of ferry } \\
\text { - Draw water } \\
\text { - Fishing } \\
\text { - Culture of wash place } \\
\text { - Pavilion } \\
\text { - Boating } \\
\text { - Culture of taste for the arts }\end{array}$ & $\begin{array}{l}\text { - Irrigation } \\
\text { - Fishery } \\
\text { - Shipping } \\
\text { - Defensive the military } \\
\text { - Flood protection }\end{array}$ \\
\hline $\begin{array}{l}\text { Beginning of } \\
\text { development }\end{array}$ & $\begin{array}{l}\text { The late period } \\
\text { of Joseon } \sim 1950 \mathrm{~s}\end{array}$ & $\begin{array}{l}\text { - Period of Japanese occupation } \\
\text { and war modernization } \\
\text { - Restoration }\end{array}$ & $\begin{array}{l}\text { - Change from waterborne traffic to land } \\
\text { traffic } \\
\text { - Follow the tradition profession }\end{array}$ & $\begin{array}{l}\text { - Dam construction } \\
\text { - Beginning of development } \\
\text { - Construction of track and bridge }\end{array}$ \\
\hline $\begin{array}{c}\text { Active } \\
\text { development }\end{array}$ & The 1960s 1980s & $\begin{array}{l}\text { - Industrialization } \\
\cdot \text { Urbanization } \\
\text { - High-speed growth } \\
\cdot \text { Unimpeded development }\end{array}$ & $\begin{array}{l}\text { - Extinction of water culture } \\
\cdot \text { Culture of civil engineering and } \\
\text { construction } \\
\text { - Artificial culture }\end{array}$ & $\begin{array}{l}\text { - Industry and water for living } \\
\text { - Focused on river planning and land } \\
\text { development in river area } \\
\text { - Uniformed organization }\end{array}$ \\
\hline $\begin{array}{l}\text { Recycle, } \\
\text { Restoration }\end{array}$ & After the 1990s & $\begin{array}{l}\text { - Deindustrialization } \\
\text { - Information age } \\
\cdot \text { Age of culture and } \\
\text { environment }\end{array}$ & $\begin{array}{l}\text { - Daily life of citizen's leisure culture and } \\
\text { activity } \\
\text { - Water sports, night view appreciation } \\
\text { - Expansion of water culture and } \\
\text { ecological experience culture }\end{array}$ & $\begin{array}{l}\text { - River basin and urban restoration } \\
\text { - Division natural stream restoration : } \\
\text { ecosystem, preservation for the river } \\
\text { scenery }\end{array}$ \\
\hline
\end{tabular}

Data: Lee and Heo, 2012; 14. Most Powerful Brands

Kwon and Cho, 2010; Kim and Lee, 2011). 그러나 수변공간 개발 양상은 1990 년대에 문화와 환경의 시대로 접어들면서 여 가활동, 수상레저, 야경감상, 생태체험과 같은 친수기능에도 관 심을 갖기 시작했다(Table 1 참조).

수변공간 개발과 관련된 연구로는 이치수 기능으로써 수변 공간의 발전과 필요성에 관한 연구(Jang et al., 2007; Oh, 2010) 와 환경친화적인 방향으로의 공간 개발과 여가 인프라 구 축을 위한 공간 활성화 방안에 관한 연구(Lee, 2009; Kwon and Cho, 2010; Kim, 2011)등이 있다. 최근에는 경관 창출 및 지역개발의 가치 상승과 지역활성화 전략으로써 수변공간이 중요시 되면서(Sheldon and Abenoja, 2001; Song et al., 2010; Kwon and Cho, 2011; Cho and Song, 2012) 수변공간 이용자 및 지역주민까지 연구대상으로 확대되고 있다. 관련 연구로는 지역개발에 있어 이용자 및 지역주민을 모두 고려한 연구(Lee et al., 1999; Kim, 2009)와 지역주민을 대상으로 공간 개발의 허용 가능한 정도를 본 연구(Kim, 2004; Jeong et al., 2007; Ko and Jeong, 2007)등이 있다. 이러한 연구들은 공통적으로 지역개발에 있어 주민을 대상으로 한 연구의 필요성을 언급하 고 있으며, 이를 토대로 본 연구에서도 수변공간 개발에 대한 지역주민의 태도를 검증하고자 하였다.

\section{2. 허용변화한계}

허용변화한계(LAC: Limits of Acceptable Change)는 Stankey et al.(1985)에 의해 계획된 개념으로 지역개발계획에서 지속가
능성의 개념을 적용하기 위한 모범적인 모델이다(Ahn et al., 2002; Oh et al., 2012). LAC 개념에 의하면 지역개발의 방향 은 지역주민 및 환경이 수용할 수 있는 '허용 변화 한계'에 대 한 파악을 전제로 하고 있다. $\mathrm{LAC}$ 는 지역의 허용 가능한 개발 형태 분석 및 향후 개발 목표설정, 전 단계에서 설정한 목표와 지역 현황 간의 관계 분석, 최적의 대안 개발, 평가 및 모니터 링의 네 단계의 결정과정을 거치며, Table 2와 같이 실무에서 활용 가능하도록 9단계로 세분화되어 있다(Stankey et al., 1985; Kim, 2003; Shin and Yoon, 2011).

$\mathrm{LAC}$ 의 단계는 각 대상지의 조건이나 제반 여건에 따라 단 계 조절이 가능하며, 국내외적으로 지역개발 단계에서 지표로 써 활용되고 있다(McCool, 1994; Kim, 2003; Diedrich et al., 2011). LAC 1 단계는 지역의 허용 가능한 개발형태 분석 및 향 후 개발에 대한 목표를 설정하는 단계로 방문객으로 인한 문제 점 파악, 자원관리자·계획자·정책수립자에 의한 문제점 파 악, 지역의 수요 · 공급 분석, 지역의 자원특성 유지를 위해 요 구되는 관리지역의 변화를 측정하고 관리하는데 지역주민의 의사가 최초로 반영되는 단계이다(Stankey et al., 1985) 이 단 계는 지역의 개발 목적 확립을 위한 중요한 단계이며, 특히 LAC 2단계의 연구에 중요한 영향을 미치기 때문에 신중하게 평가되어야 한다(Kim, 2003).

$\mathrm{LAC} 2$ 단계는 휴양자원 등급화 과정으로 접근방법은 수용력 과 휴양기회분포(ROS: Recreation Opportunity Spectrum)로 나뉜다. 먼저 수용력의 개념은 1936년 초에 야외 레크리에이 션 분야에서 생물학적 구성요소와 레크리에이션 경험의 질을 반 
Table 2. Process of LAC planning

\begin{tabular}{|c|c|c|c|}
\hline Decision process & Step & Contents & Specific contents \\
\hline $\begin{array}{l}\text { Analysis for acceptable } \\
\text { development type in area and } \\
\text { the establishment of target for } \\
\text { future development }\end{array}$ & Step 1 & $\begin{array}{l}\text { Characteristics of area } \\
\text { concern and issue of area }\end{array}$ & $\begin{array}{l}\text { Understanding of problems from visitors/ Resource manager and planner/ } \\
\text { Understanding of problem by policy maker/ Analysis of demand and supply in } \\
\text { an area/ Management which is demanded for maintenance of resource } \\
\text { characteristic in area }\end{array}$ \\
\hline \multirow{5}{*}{$\begin{array}{l}\text { Relation analysis between the } \\
\text { goal settled in the Step } 1 \text { and } \\
\text { local current state }\end{array}$} & Step 2 & $\begin{array}{l}\text { Classification of resort } \\
\text { resource(opportunity class) }\end{array}$ & $\begin{array}{l}\text { Selection for name and type of opportunity ranking through reviewing of local } \\
\text { problems which is collected in Step 1/ Setting of ranking for resort resource }\end{array}$ \\
\hline & Step 3 & $\begin{array}{l}\text { Suggestion of resource and } \\
\text { social indicator }\end{array}$ & $\begin{array}{l}\text { Suggestion of resource and social condition for management/ Use of } \\
\text { quantitative criterion's indicator }\end{array}$ \\
\hline & Step 4 & $\begin{array}{l}\text { Inventory of resource and } \\
\text { social condition }\end{array}$ & $\begin{array}{l}\text { Mapping and record of data/ Provision of existed data for analysis of resort } \\
\text { resource ranking and standardization of indicator }\end{array}$ \\
\hline & Step 5 & $\begin{array}{l}\text { Specific standards for } \\
\text { resource and social indicator }\end{array}$ & Establishment of desirable criterion based on listed data \\
\hline & Step 6 & $\begin{array}{l}\text { Set-up of acceptable } \\
\text { limitation after setting } \\
\text { standard indicator }\end{array}$ & $\begin{array}{l}\text { Solving of general problem in area/ Settlement of acceptable limitation for } \\
\text { desirable resort resource ranking }\end{array}$ \\
\hline \multirow{2}{*}{ Creation of optimal alternative } & Step 7 & $\begin{array}{l}\text { Suggestion of practical } \\
\text { management action }\end{array}$ & $\begin{array}{l}\text { Parallel of analysis for not only administrative expense, but also tourists and } \\
\text { environmental effects }\end{array}$ \\
\hline & Step 8 & Selection of an alternative & $\begin{array}{l}\text { Management is demanded of being proved in the Step } 7 \text { as the final selection } \\
\text { is the result of characteristics and issues of area based on Step } 1 .\end{array}$ \\
\hline Evaluation and monitoring & Step 9 & $\begin{array}{l}\text { Implementation of selected } \\
\text { altemative and establishment } \\
\text { of monitoring program }\end{array}$ & $\begin{array}{l}\text { Monitoring provides the feedback process for effective management and is } \\
\text { demanded of other criterion or strict application }\end{array}$ \\
\hline
\end{tabular}

Data: Kim, 2003: 59. Rewriting

영시키는 행동 구성요소를 정의하기 위해 활용되었다(Saveriades, 2000). 수용력은 자연환경의 훼손을 최소화하고 최적의 이용수 준을 결정하기 위해 적정 이용자 수를 찾는데 주력하였지만, 결과 값에 대한 객관적 근거가 부족하다는 지적을 받고 있다 (Choi, 2000). ROS는 야외 레크리에이션, 관광 계획가 및 관리 자를 돕기 위해 개발된 것으로 ROS등급에 따른 이용자 활동과 물리적 환경의 차이를 분석하고, 이를 연계시키기 위한 방법이 다(Jeong, 2005). ROS는 토지적성평가 방법을 토대로 준원시 지역, 자연지역, 농촌지역, 도시지역 등으로 분류되는데, 이는 적용범위, 공공참여의 한계, 생태적 계획구조 결여 등의 한계를 가지고 있으며, 이에 대한 검증이 필요한 실정이다(Jeong et al., 2007). 이러한 관점에서 휴양자원 등급화 과정에서 겪고 있는 적용 범위에 대한 문제는 LAC 1단계 과정에서 해결 가능 할 것으로 사료된다.

이에 따라 본 연구에서는 LAC 1 단계를 이용하여 허용 가능 한 수변공간 개발 형태를 도출하고, 향후 수변공간의 개발 및 관리 목적을 설정함으로써, LAC 2단계에 도입 가능한 지역범 위를 설정하고자 한다.

\section{3. 주민태도}

태도란 특정 대상 혹은 상황에 대해 지속적으로 갖는 신념조 직으로 개인의 반응 형태를 지칭한다(Cho and $\mathrm{Kim}, 2002)$. 이는
어떤 사람의 신념에 있어서 옳고 그름, 좋고 나쁨, 바람직함의 확신 정도를 나타내고 있는 지식, 신념의 대상에 대한 정서적 반응, 어떤 형식으로 행동하려는 성향으로써 우호적이거나 비우 호적인 반응을 나타내는 것을 의미한다(Aizen, 1988; Lee, 2004).

과거 방문객의 태도에 초점을 맞춰오던 지역개발 분야에서 도 1970년대 중반 이후로 지역주민의 태도에 관한 연구가 수행 되기 시작하였다(Cho and Kim, 2002; Kang, 2002; Yeoju-Gun, 2007). 특히, 지역주민의 태도는 의지에 따라 개발 방식 및 진 행에 영향을 미칠 수 있기 때문에, 주민태도에 관한 연구의 필 요성이 강조되고 있다(Perdue et al., 1995). 주민태도에 관한 연구동향은 과거 관광개발, 지역개발에 관한 연구가 주를 이루 던 것이 사회환경적 비용에 관한 연구, 경제적 피해가 주민저 항에 미치는 영향에 관한 연구 등으로 변화되고 있는 추세이다 (Lee et al., 2012; Yoo et al., 2012). 이와 관련하여 사회교환이 론(Social Exchange Theory)이 활용되고 있으며, 지역주민의 거주특성 및 일반특성과 같은 인구통계학적 특성에 따라 지역 개발에 대한 태도가 다르게 나타남을 전제한다(Cho and Kim, 2002; Teye et al., 2002; Huh et al., 2005; Choi and Lee, 2006; Kaltenborn et al., 2008; Oh and Yoon, 2009; Jang, 2012; Látková and vogt, 2012). 이는 지역주민의 태도나 인식 에 따라 주민과 방문객 사이에는 비대칭적으로 비용(부정적 영향) 과 편익(긍정적 영향)이 발생하게 되며 그 결과, 주민태 도는 긍정적이거나 부정적으로 나타나게 되는 것을 의미한다 
(Ap, 1992; Zamani-Farahani and Musa, 2008). 편익이 비용보 다 클 경우에 지역주민들은 사회적 교환을 고려하게 되며(Allen et al., 1993), 비용이 편익보다 높을 때는 부정적 태도를 보이 게 되는 등, 동일 개발상에서도 주민간의 태도에는 차이가 발 생하게 된다(Choi and Kim, 2005). 일반적으로 개인의 경제적 이익이 긍정적인 태도와 관련성이 있다고 보지만(Ap, 1992; Andereck and Vogt, 2000), Mbaiwa and Stronza(2011)의 연 구에서는 긍정적인 태도는 경제적 이익에서만 오는 것이 아니 라 다른 요인에 의해서도 나타난다고 보고 있다. 특히 주민의 인구통계학적 특성 중 거주특성은 지역주민의 태도에 영향을 미치는 것으로 나타나는데, 일반적으로 거주지역과 개발지역이 멀수록 긍정적 태도를 가지며, 개발에 대해 우호적인 태도를 가지고 있는 것으로 확인되었다(Madrigal, 1993; Choi and Lee, 2006). 하지만 반대로 또 다른 거주지역을 대상으로 한 연 구에서는 개발지역에서 멀수록 부정적 태도를 갖는 결과가 나 오는 등(Belisle and Hoy, 1992; Mansfeld, 1992) 연구마다 상 이하게 나타나는 것을 확인할 수 있다. 즉, 지역마다 거주특성 에 따른 주민의 태도가 다르게 나타나는 것으로 해석할 수 있 으며, 허용 가능한 수변공간 개발 시, 거주특성에 따른 지역주 민의 태도 차이의 검증단계를 거쳐야 할 것이다.

이 외에도 사회교환 이론에 관한 선행 연구를 종합해 봤을 때, 주민태도는 개인적인 요인에 의해 결정되는 것이며, 긍정적 태도를 가지고 있으면 개발에 긍정적인 영향을 주고, 부정적 태도를 가지고 있으면 부정적 영향을 끼치는 것을 확인할 수 있었다(Vargas-Sánchez et al., 2011). 따라서 본 연구에서는 허용 가능한 수변공간 개발 형태를 도출하기 위해 수변공간 개 발에 대한 주민태도를 분석하였다. 또한 거주특성에 따른 주민 태도 차이분석을 실시하여 휴양자원 등급화의 적용범위를 선 정하였다.

\section{III. 연구 방법}

\section{1. 연구 문제}

주민특성이 주민태도에 영향을 미치는 중요 변수라는 것이 선행연구를 통해서 반복적으로 확인되었다(Mbaiwa and Stronza, 2011; Látková and Vogt, 2012). 즉, 주민태도에 따라 허용 가 능한 수변공간 개발 형태는 달라질 수 있다고 이해할 수 있다. 이에 따라 본 연구에서는 LAC 1단계에 따라 주민태도를 통해 허용 가능한 수변공간 개발 형태를 파악하기 위한 연구문제를 설정하였다. 또한 사회교환이론을 검증하고 휴양자원 등급화의 적용범위를 제시하기 위해 Cho et al.(2005)의 연구를 근거로 가설을 설정하여 거주특성과 주민태도 간의 차이를 분석하였다. 연구문제 1) 주민태도 요인은 허용 가능한 수변공간 개발 형

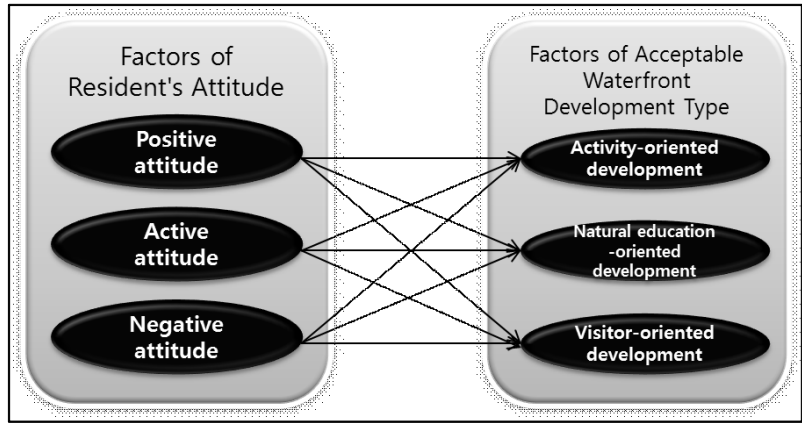

Figure 1. Model in research question

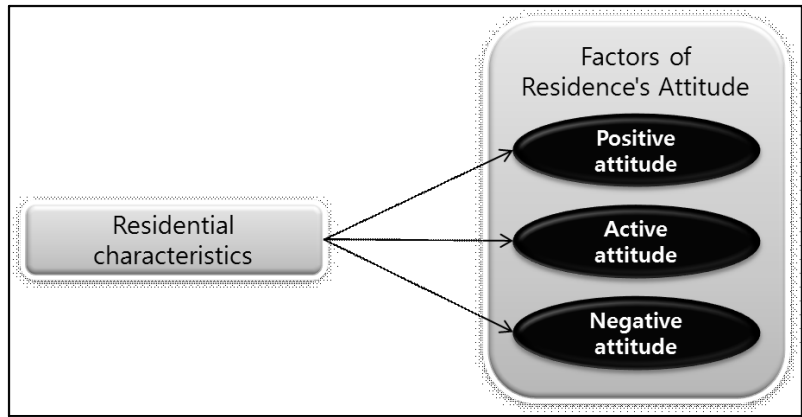

Figure 2. Model in research question 2

태요인과 어떠한 영향 관계를 나타내는가?

연구문제 2) 거주특성에 따라 수변공간 개발에 대한 주민태 도요인은 차이가 있는가?

(1) 가설 $1:$ 고향여부에 따라 수변공간 개발에 대한 주민태 도요인은 차이가 있다.

(2) 가설 $2:$ 거주기간에 따라 수변공간 개발에 대한 주민태 도요인은 차이가 있다.

(3) 가설 $3:$ 거주지역에 따라 수변공간 개발에 대한 주민태 도요인은 차이가 있다.

(4) 가설 4 : 수변공간 개발관련 부동산 소유 여부에 따라 수변공간 개발에 대한 주민태도요인은 차이가 있다.

\section{2. 연구 설계}

1) 연구 대상지

연구 대상지인 경기도 여주시는 서울과 인접지역으로 경기 도 동남내륙권에 속하며, 강원도와 충청북도의 경계에 위치한 지역으로 총 면적은 약 $607 \mathrm{~km}^{2}$ 이며, 주민등록 인구는 약 11 만 명으로 구성되어 있다(Figure 3, Table 3 참조). 여주군은 2013 년 9월 23일 '여주시'로 승격하였으며, 이에 따라 종합적 도시 계획을 필요하고 있고, 2020년 여주군 기본계획(Yeoju-Gun, 2007 ) 기준에 맞추어 여주시 전역을 1 개의 중심생활권(여주중 심생활권)과 3 개의 지역생활권(대신지역생활권, 북내지역생활 


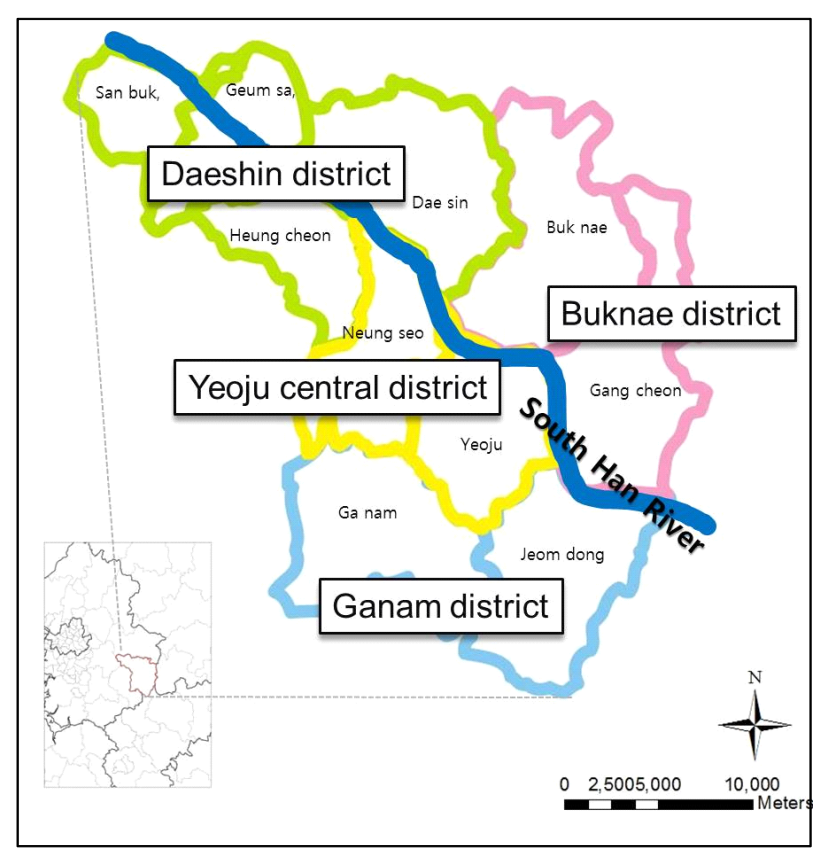

Figure 3. Yeoju residential districts

권, 가남지역생활권)으로 구분하고 있다. Yeoju-Gun(2007)과 Ministry of Land(2007)에 따르면 여주중심생활권은 여주시의 중심기능 및 주거 - 교육·행정- 문화 - 관광의 기능을 가지고 있으며, 2011 2012년 백석리섬, 현암, 양섬, 연양, 내양지구에 총 면적 $2.34 \mathrm{~km}^{2}$ 의 수변공간이 조성되었다. 대신지역생활권은 주거 및 관광-휴양과 자연환경보전의 기능을 가진 지역이다. 대신지역생활권에 조성된 수변공간은 전북, 당남, 당남리섬, 여 주 저류지, 양촌, 계신/복대, 가산, 천남지구를 포함하는 곳으로 총 면적이 $4.93 \mathrm{~km}^{2}$ 으로 4 개의 생활권중 가장 넓은 면적의 수변 공간이 개발되었다. 북내지역생활권은 주거- 관광-휴양-공 업-체육의 기능을 가지고 있다. 북내지역생활권에 조성된 수 변공간은 가야, 굴암, 강천섬 지구를 포함하는 곳으로, 총 면적

Table 3. Classification of Yeoju residential districts(2013.02)

\begin{tabular}{c|c|c|c|c}
\hline $\begin{array}{c}\text { Residential } \\
\text { districts }\end{array}$ & $\begin{array}{c}\text { Administrative } \\
\text { district }\end{array}$ & $\begin{array}{c}\text { Area } \\
\left(\mathrm{km}^{2}\right)\end{array}$ & $\begin{array}{c}\text { Population } \\
(\%)\end{array}$ & $\begin{array}{c}\text { Population } \\
\text { density } \\
\left(\mathrm{a} \text { person } / \mathrm{km}^{2}\right)\end{array}$ \\
\hline $\begin{array}{c}\text { Yeoju central } \\
\text { district }\end{array}$ & Yeoju, Neung seo & 109.7 & $\begin{array}{c}49,351 \\
(55.8)\end{array}$ & 556.7 \\
\hline Daeshin district & $\begin{array}{c}\text { San buk, Geum sa, } \\
\text { Dae sin, Heung cheon }\end{array}$ & 194.7 & $\begin{array}{c}18,477 \\
(16.9)\end{array}$ & 94.9 \\
\hline Buknae district & Buk nae, Gang cheon & 156.5 & $\begin{array}{c}21,078 \\
(19.3)\end{array}$ & 134.3 \\
\hline Ganam district & Ga nam, Jeom dong & 147.0 & $\begin{array}{c}8,826 \\
(8.1)\end{array}$ & 60.0 \\
\hline & Total & 607.9 & $\begin{array}{c}109,447 \\
(100)\end{array}$ & 183.7 \\
\hline
\end{tabular}

Data: Yeoju-Gun, 2007: 108. Rewriting

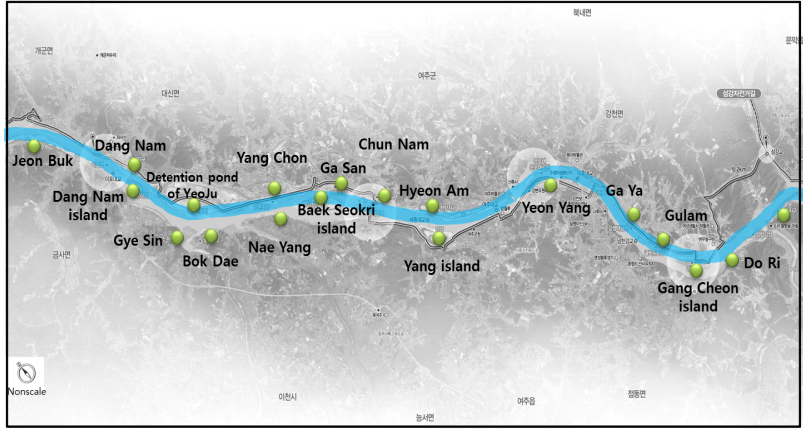

Figure 4. 2011 2012 Current situation for creation of waterfront in Yeoju

이 $1.32 \mathrm{~km}^{2}$ 이다. 가남지역생활권은 여주시의 부도심으로써 주 거·공업·물류·체육의 기능을 한다. 가남지역생활권에 조성 된 수변공간은 도리, 삼합지구를 포함하는 곳으로 총 $0.46 \mathrm{~km}^{2}$ 가 개발되었다. 여주시의 수변공간은 남한강 가운데 가장 긴 연접구간인 $38.9 \mathrm{~km}$ 을 포함하고 있을 뿐만 아니라, 여주시의 모 든 생활권을 지나고 있어 수변공간 개발에 민감하게 반응할 것 으로 보인다. 또한 수도권정비계획법상 자연보전권역으로 개발 이 규제되어 왔던 수변공간이 2008년 이후로 규제가 완화되어 Figure 4와 같이 새롭게 개발 공간이 증가하였기 때문에 연구 대상지로 적합하다고 판단하였다.

\section{2) 변수의 조작적 정의 및 설문지 구성}

연구에서 사용된 주요 변수는 수변공간 개발에 대한 주민태 도, 허용 가능한 수변공간 개발 형태, 인구통계학적 특성이며, 개별 변수에 대한 조작적 정의는 다음과 같다. 먼저 '수변공간' 이란 강변의 수면부와 육지부가 유기적으로 결합되어 전이되 는 영역으로 주민여가 활동의 장으로 활용되는 공간을 의미한 다(Baek and Noh, 2006; Lee et al., 2012). 수변공간 개발에 대한 주민태도는 수변공간 개발로부터 파생되는 경제, 사회 문화, 환경적 영향에 대하여 긍정적 또는 부정적으로 반응하는 주민의 성향을 의미한다(Cho and Kim, 2002; Lee, 2004; YeojuGun, 2007). 허용 가능한 수변공간 개발 형태는 지역주민들이 허용할 수 있는 수변공간 개발 형태를 설정하기 위한 개념으로 활용하였다(Lime, 1970; Frissel and Stankey, 1972; Kim, 2003). 인구통계학적 특성은 여주시 지역주민의 일반사항과 거 주특성을 의미하며, 사회교환 이론에 따라 수변공간 개발에 대 한 주민들의 태도를 파악하기 위해 활용하였다.

주민태도에 관한 설문 조사 항목은 선행연구를 통해 신뢰성 이 검증된 척도(Jeong, 2005)를 적용하였다. 허용 가능한 수변 공간 개발 형태 항목 역시 선행연구에서 신뢰성이 검증된 척도 를 적용하였으며(Ahn et al., 2002), 허용 가능한 수변공간의 개발 형태를 알아보기 위한 연구 목적에 따라 1 개 문항을 수정 하여 적용하였다. 마지막으로 주민특성에 관한 문항은 선행연 
Table 4. Questionnaire structure

\begin{tabular}{|c|c|c|c|}
\hline Scale & Items & Contents & Reference \\
\hline $\begin{array}{l}\text { Residence's } \\
\text { attitude }\end{array}$ & 12 & $\begin{array}{l}\text { Residence's attitude for waterfront } \\
\text { development }\end{array}$ & $\begin{array}{l}\text { Jeong } \\
(2005)\end{array}$ \\
\hline $\begin{array}{c}\text { Acceptable types } \\
\text { of waterfront } \\
\text { development }\end{array}$ & 19 & $\begin{array}{l}\text { Acceptable waterfront development } \\
\text { type }\end{array}$ & $\begin{array}{c}\text { Ahn et al. } \\
(2002)\end{array}$ \\
\hline \multirow{2}{*}{$\begin{array}{c}\text { Residents' } \\
\text { characteristics }\end{array}$} & \multirow{2}{*}{9} & $\begin{array}{l}\langle\text { Demographic characteristic }\rangle \\
\text { Gender, Age, Marital status, Work, } \\
\text { Income }\end{array}$ & \multirow{2}{*}{$\begin{array}{c}\text { Jeong et al } \\
(2007), \\
\text { Lee et al. } \\
(2012)\end{array}$} \\
\hline & & $\begin{array}{l}\text { 〈Residential characteristics }\rangle \\
\text { Home town, Residence period, Residence } \\
\text { district, Ownership of real estate }\end{array}$ & \\
\hline
\end{tabular}

구를 통해 신뢰성이 검증된 척도(Jeong et al., 2007; Lee et al., 2012)를 전문가 검증을 토대로 재구성 하였다(Table 4 참조).

\section{3) 자료수집 및 분석}

본 연구는 여주시 지역주민들을 대상으로 수변공간에 대한 허용 가능한 개발 정도를 파악하기 위해 선행연구 및 문헌고찰 을 통해 작성된 도구로 설문조사를 실시하였다. 조사는 2012년 10 월 12 일부터 10 월 14 일까지 현장방문을 하여 편의추출방식 으로 설문조사를 시행하였다. 배부된 총 300 부의 설문지 중 261 부가 회수되었으며, 불성실한 응답 및 누락된 설문 문항의 21 부를 제외한 240 부를 SPSS 12.0 의 통계프로그램을 사용해 분석 하였다.

\section{IV. 결과 및 고찰}

\section{1. 여주시 지역주민의 인구통계학적 특성}

\section{1) 여주시 지역주민의 일반특성}

여주시 지역주민의 일반특성 파악을 위해 성별, 연령, 혼인여 부, 직업, 월 소득을 조사하였으며, 이는 조사 표본의 특성을 파 악한 것으로 연구 결과를 일반화시키기 위한 근거자료로 제시될 수 있다. 설문 응답자는 남자 126명(52.5\%), 여자 114명(47.5\%) 으로 남자의 빈도가 조금 높게 분포되었으며, 분석 내용은 Table 5 와 같았다. 이 결과는 Yeoju-Gun(2011)의 남자 $(50.4 \%)$, 여자 (49.6\%)와 유사한 값을 가지는 것으로 확인되었다.

\section{2) 여주시 지역주민의 거주특성}

여주시 지역주민의 거주특성 파악을 위해 고향 여부, 거주기 간, 거주지역, 수변공간 개발 관련 부동산 소유 여부를 조사하 였다. 조사 대상자 240 명 중 여주시가 '고향이다'라고 응답한 사람은 130 명 $(54.2 \%$ )이었으며, 거주한 기간은 11 20년이 53명 (22.1\%)으로 가장 많은 빈도를 나타냈고, 6 10년이 28명(11.7\%)
Table 5. Demographic characteristics

\begin{tabular}{|c|c|c|c|}
\hline & Division & Freq. & $\%$ \\
\hline \multirow{3}{*}{ Gender } & Male & 126 & 52.5 \\
\hline & Female & 114 & 47.5 \\
\hline & Total & 240 & 100.0 \\
\hline \multirow{7}{*}{ Age } & $\geq 19$ & 11 & 4.6 \\
\hline & $20 \sim 29$ & 32 & 13.3 \\
\hline & $30 \sim 39$ & 61 & 25.4 \\
\hline & $40 \sim 49$ & 67 & 27.9 \\
\hline & $50 \sim 59$ & 53 & 22.1 \\
\hline & $>59$ & 16 & 6.7 \\
\hline & Total & 240 & 100.0 \\
\hline \multirow{3}{*}{ Marital status } & Married & 185 & 77.1 \\
\hline & Unmarried & 55 & 22.9 \\
\hline & Total & 240 & 100.0 \\
\hline \multirow{11}{*}{ Work } & Housewife & 53 & 22.1 \\
\hline & Own business & 43 & 17.9 \\
\hline & Profession & 28 & 11.7 \\
\hline & Company worker & 26 & 10.8 \\
\hline & Agriculture and fishery & 24 & 10.0 \\
\hline & Student & 21 & 8.8 \\
\hline & Others & 21 & 8.8 \\
\hline & Production employee & 10 & 4.2 \\
\hline & Government employee & 7 & 2.9 \\
\hline & Retired/unemployed & 7 & 2.9 \\
\hline & Total & 240 & 100.0 \\
\hline \multirow{6}{*}{$\begin{array}{l}\text { Monthly } \\
\text { income }\end{array}$} & $\geq$ One million won & 23 & 9.6 \\
\hline & $\geq$ Two million won & 59 & 24.6 \\
\hline & $\geq$ Three million won & 74 & 30.8 \\
\hline & $\geq$ Four million won & 49 & 20.4 \\
\hline & Five million won $<$ & 35 & 14.6 \\
\hline & Total & 240 & 100.0 \\
\hline
\end{tabular}

으로 가장 낮은 빈도를 나타냈다. Yeoju-Gun(2011)에서도 20 년 이상의 장기거주자 $(59.0 \%)$ 가 10 년 이하의 거주자 $(41.1 \%)$ 보다 비율이 높은 것을 확인할 수 있었다. 거주지역은 여주중 심생활권이 133 명 $(55.4 \%)$ 으로 가장 높은 빈도를 차지하였으 며, 다음으로 대신지역생활권 61 명(25.4\%), 가남지역생활권 24 명 $(10.0 \%)$, 북내지역생활권 22 명 $(9.2 \%)$ 순으로 분포하였다. 응 답자 중 수변공간 개발 관련 지역에 소유한 부동산이 있는 주 민은 128 명 (53.3\%)으로 소유하고 있지 않은 주민보다 많게 나 타났다(Table 6 참조).

\section{2. 측정변수들의 요인분석}

연구문제 해결을 위해 수변공간 개발에 대한 주민태도와 허 
Table 6. Residential characteristics of respondents

\begin{tabular}{|c|c|c|c|}
\hline \multicolumn{2}{|c|}{ Division } & Freq. & $\%$ \\
\hline \multirow{3}{*}{ Home town } & Home town & 130 & 54.2 \\
\hline & Non-home town & 110 & 45.8 \\
\hline & Total & 240 & 100.0 \\
\hline \multirow{7}{*}{ Residence period } & $\geq 5$ years & 43 & 17.9 \\
\hline & $6 \sim 10$ years & 28 & 11.7 \\
\hline & $11 \sim 20$ years & 53 & 22.1 \\
\hline & $21 \sim 30$ years & 45 & 18.8 \\
\hline & $31 \sim 40$ years & 34 & 14.2 \\
\hline & $>40$ years & 37 & 15.4 \\
\hline & Total & 240 & 100.0 \\
\hline \multirow{5}{*}{ Residence district } & Yeoju central district & 133 & 55.4 \\
\hline & Daeshin district & 61 & 25.4 \\
\hline & Buknae district & 22 & 9.2 \\
\hline & Ganam district & 24 & 10.0 \\
\hline & Total & 240 & 100.0 \\
\hline \multirow{3}{*}{$\begin{array}{l}\text { Ownership of } \\
\text { waterfront real estate }\end{array}$} & Owner & 128 & 53.3 \\
\hline & Non-owner & 112 & 46.7 \\
\hline & Total & 240 & 100.0 \\
\hline
\end{tabular}

용 가능한 수변공간 개발 형태에 대한 요인분석을 실시하여 주 요변수로 활용하였다. 항목들은 주성분분석을 사용하였으며, 고 유값(Eigenvalue) 1 이상을 기준으로 Varimax 회전을 실시하 였다.

\section{1) 수변공간 개발에 대한 주민태도 요인분석}

수변공간 개발에 대한 주민태도 요인분석은 주민태도에 대 한 12 개 항목 전체를 대상으로 요인분석을 실시하였다(Table 7 참조). 요인분석 결과, 전체 요인의 분산 설명력은 약 $66 \%$ 이며, 수변공간 개발에 대한 주민태도는 총 3 개의 요인으로 분류되었 다. 3 개의 요인은 모두 1 이상의 고유값을 갖고 있으며, 주민태 도의 전체 항목에 대한 Cronbach's $\alpha$ 값이 .800 의 유의미한 결 과 값을 나타내어 신뢰도와 타당성 측면에서 유의성이 검증되 었다.

도출된 3개의 요인은 항목 특성에 따라 각각 '긍정적 태도 (Cronbach's $\alpha=.860$ )', '적극적 태도(Cronbach's $\alpha=.848)$ ', '부 정적 태도(Cronbach's $\alpha=647$ )'로 명명하였다. 이 결과는 요 인 항목의 내용적 측면에서는 선행연구와 유사성을 나타냈지 만, 제거되는 항목 없이 12 개의 모든 항목이 3 개의 요인으로 분 류되었으며, 요인 간 세부 항목의 내용이 다르다는 점에서 선 행연구와의 차별성을 가진다.

2) 허용 가능한 수변공간 개발 형태 요인분석

여주시 지역주민의 허용 가능한 수변공간 개발 형태의 요인
Table 7. Resident's attitudes types of waterfront development

\begin{tabular}{|c|c|c|c|}
\hline Items & $\begin{array}{l}\text { Positive } \\
\text { attitudes }\end{array}$ & $\begin{array}{l}\text { Active } \\
\text { attitudes }\end{array}$ & $\begin{array}{l}\text { Negative } \\
\text { attitudes }\end{array}$ \\
\hline $\begin{array}{l}\text { Environmental condition and tourism } \\
\text { resource are properly used in the } \\
\text { process of waterfront development. }\end{array}$ & .835 & .137 & .024 \\
\hline $\begin{array}{l}\text { Sustainable planning and management } \\
\text { for waterfront development are properly } \\
\text { performed. }\end{array}$ & .808 & .246 & -.040 \\
\hline $\begin{array}{l}\text { Satisfy with development policy of } \\
\text { waterfront which administrative agency } \\
\text { promotes. }\end{array}$ & .750 & .159 & -.190 \\
\hline $\begin{array}{l}\text { Resident participation is well performed } \\
\text { when accepting an opinion for water- } \\
\text { front development in area. }\end{array}$ & .744 & .141 & .082 \\
\hline $\begin{array}{l}\text { Satisfy with waterfront development } \\
\text { when considering synthetically. }\end{array}$ & .717 & .317 & -.183 \\
\hline $\begin{array}{l}\text { Many tourists will visit when distri- } \\
\text { buting information about waterfront. }\end{array}$ & .175 & .873 & -.034 \\
\hline $\begin{array}{l}\text { My region can accommodate more } \\
\text { tourists than other area. }\end{array}$ & .372 & .754 & .006 \\
\hline $\begin{array}{l}\text { The local leader is needed for im- } \\
\text { proving the waterfront environment. }\end{array}$ & .039 & .739 & -.096 \\
\hline $\begin{array}{l}\text { My area will have advantages } e^{-}{ }^{-} \\
\text {nomically when increasing waterfront } \\
\text { development. }\end{array}$ & .378 & .709 & -.064 \\
\hline I support new waterfront development. & .171 & 690 & -.180 \\
\hline $\begin{array}{l}\text { My area get damaged due to past } \\
\text { waterfront development. }\end{array}$ & -.076 & -.040 & .846 \\
\hline $\begin{array}{l}\text { I have been opposed to the water- } \\
\text { front development of my community } \\
\text { in the past. }\end{array}$ & -.035 & -.171 & .840 \\
\hline Cronbach's $\alpha$ & .860 & .848 & .647 \\
\hline Eigenvalue & 4.968 & 1.660 & 1.363 \\
\hline Percentage variance & 41.398 & 13.836 & 11.359 \\
\hline Cumulative percentage variance & 41.398 & 55.234 & 66.593 \\
\hline
\end{tabular}

분석은 총 19 개 항목 중 요인 적재값이 기준에 못 미치는 1 가 지 항목과 Cronbach's $\alpha$ 값이 .5 이하로 신뢰도가 낮은 2 개 항 목을 제외한 총 16개의 항목을 대상으로 실시하였다(Table 8 참조). 분석결과, 전체 요인의 분산 설명력은 약 $58 \%$ 이며, 허 용 가능한 수변공간 개발 형태, 전체 항목에 대한 Cronbach's $\alpha$ 값이 .899의 유의미한 결과 값을 나타내어 신뢰도와 타당성 측면에서 유의성이 검증되었다.

도출된 3개의 요인은 특성에 따라 각각 '활동중심개발(Cronbach's $\alpha=.850)$ ', '자연교육중심개발(Cronbach's $\alpha=.866)$ ', '방문객중심개발 (Cronbach's $\alpha=.592)$ '로 명명하였다. 활동중 심개발과 자연교육중심개발의 경우 선행연구와 유사한 결과를 나타냈지만, 방문객중심개발 요인에서 선행연구와 차별성을 나 타냈다. 
Table 8. Factor analysis of acceptable waterfront development type

\begin{tabular}{|c|c|c|c|}
\hline Items & $\begin{array}{c}\text { Activity } \\
\text {-oriented } \\
\text { development }\end{array}$ & $\begin{array}{c}\text { Natural } \\
\text { education } \\
\text {-oriented } \\
\text { development }\end{array}$ & $\begin{array}{c}\text { Visitor } \\
\text {-oriented } \\
\text { development }\end{array}$ \\
\hline Riverside resort & .790 & .004 & .163 \\
\hline $\begin{array}{l}\text { Facility including an amusement } \\
\text { park }\end{array}$ & .784 & -.016 & .183 \\
\hline $\begin{array}{l}\text { Large visitor groups throughout } \\
\text { the year }\end{array}$ & .727 & .197 & .073 \\
\hline $\begin{array}{l}\text { Restaurant development for many } \\
\text { visitors }\end{array}$ & .705 & .283 & .074 \\
\hline Young visitors to the local area & .603 & .244 & .230 \\
\hline $\begin{array}{l}\text { Development the historical site } \\
\text { for visitors }\end{array}$ & .559 & .329 & .187 \\
\hline Camping ground & .555 & .458 & -.042 \\
\hline $\begin{array}{l}\text { A place where visitors can see the } \\
\text { undeveloped natural environment }\end{array}$ & .031 & .766 & .102 \\
\hline $\begin{array}{l}\text { Guide which provided to the } \\
\text { nature observer }\end{array}$ & .276 & .758 & .230 \\
\hline $\begin{array}{l}\text { A natural environment education } \\
\text { facility for visitors }\end{array}$ & .271 & .756 & .232 \\
\hline $\begin{array}{l}\text { Increased space for wild animal } \\
\text { observation }\end{array}$ & .082 & .737 & .209 \\
\hline Family visitors with children & .325 & .579 & 429 \\
\hline $\begin{array}{l}\text { The provision of accessibility } \\
\text { to the attractive for visitors }\end{array}$ & .467 & .532 & .217 \\
\hline $\begin{array}{l}\text { Day trips only } \\
\text { (no overnight stays) }\end{array}$ & .218 & .241 & .730 \\
\hline Elderly or retired visitors & -.005 & .208 & .666 \\
\hline Long-stay visitors & .265 & .123 & .657 \\
\hline Cronbach's $\alpha$ & .850 & .866 & .592 \\
\hline Eigenvalue & 6.478 & 1.779 & 1.057 \\
\hline Percentage variance & 40.490 & 11.121 & 6.607 \\
\hline Cumulative percentage variance & 40.490 & 51.611 & 58.218 \\
\hline
\end{tabular}

\section{3. 수변공간 개발에 대한 주민태도와 허용 가능한 수변공간 개발 형태 간의 관계}

도출 된 수변공간 개발에 대한 주민태도 요인이 허용 가능한 수변공간 개발 형태 요인에 영향을 미치는지를 파악하기 위해 회귀분석을 실시하였다. 먼저 주민태도 요인이 '활동중심개발' 형태에 영향을 미치는지를 알아보기 위해 '긍정적 태도', '적극 적 태도', '부정적 태도'를 독립변수로 두고, '활동중심개발' 형 태를 종속변수로 두어 다중회귀분석을 실시하였다(Table 9 참 조). 분석결과, '긍정적 태도'의 경우 유의확률 . 674 로 '활동중심 개발에 영향을 주지 않는 것으로 분석되었다( $p<.05)$. 이는 Vargas-Sánchez et al.(2011)에 따라 '활동중심개발' 형태가 장 기적인 관점에서 수변공간 개발에 긍정적 효과를 주지 못 하기
때문이라고 해석할 수 있다. '적극적 태도'의 유의확률은 .000으 로 긍정적인 영향을 미치는 것으로 나타났으며 ( $p \times .05)$, '부정적 태도'는 유의확률 .005로 유의수준 .05에서 '활동중심개발'에 영 향을 주는 것으로 나타났지만, 부정적인 영향을 미치는 것으로 분석되었다. '부정적 태도' 요인의 경우 생물 다양성을 보존하 기 위해 발생하는 경우가 있는 것으로 보아(Mbaiwa and Stronza, 2011) '적극적 태도' 요인보다 활동중심개발에 대해 소극적 성 격을 지니고 있기 때문이라고 해석할 수 있다.

다음으로 주민태도 요인이 '자연교육중심개발' 형태에 영향 을 미치는지를 알아보기 위해 '긍정적 태도', '적극적 태도', '부 정적 태도'를 독립변수로 두고, '자연교육중심개발' 형태를 종 속변수로 두어 다중회귀분석을 실시하였다(Table 9 참조). 분 석결과 ‘긍정적 태도', '적극적 태도', '부정적 태도' 모두 유의수 준 .05 이하에서 유의한 값을 나타냈다. 그 중에서 '적극적 태 도'의 표준화계수는 .353으로 주민태도 중 '자연교육중심개발'에 가장 큰 영향을 끼치는 것으로 나타났다. 반면, '부정적 태도’는

Table 9. Regression analysis of attitudes for waterfront development and acceptable development type

\begin{tabular}{|c|c|c|c|c|c|c|}
\hline \multirow{2}{*}{$\begin{array}{l}\text { Dependent } \\
\text { variable }\end{array}$} & \multirow{2}{*}{$\begin{array}{c}\text { Independent } \\
\text { variable }\end{array}$} & \multicolumn{2}{|c|}{$\begin{array}{c}\text { Unstandardized } \\
\text { coefficients }\end{array}$} & \multirow{2}{*}{\begin{tabular}{|c|}
$\begin{array}{c}\text { Standardized } \\
\text { path coefficients }\end{array}$ \\
$\beta$
\end{tabular}} & \multirow{2}{*}{$t$} & \multirow{2}{*}{ Sig } \\
\hline & & B & $\begin{array}{c}\text { Standard } \\
\text { error }\end{array}$ & & & \\
\hline \multirow{5}{*}{$\begin{array}{c}\text { Activity- } \\
\text { oriented } \\
\text { development }\end{array}$} & (Constant) & 2.477 & .269 & & 9.204 & .000 \\
\hline & $\begin{array}{l}\text { Positive } \\
\text { attitudes }\end{array}$ & .028 & .067 & .028 & .421 & .674 \\
\hline & $\begin{array}{l}\text { Active } \\
\text { attitudes }\end{array}$ & .402 & .062 & .428 & 6.433 & $.000^{*}$ \\
\hline & $\begin{array}{l}\text { Negative } \\
\text { attitudes }\end{array}$ & -.144 & .051 & -.164 & -2.848 & $.005^{*}$ \\
\hline & \multicolumn{6}{|c|}{$R^{2}=257, F=27.252$, Sig. $=.000$} \\
\hline \multirow{5}{*}{$\begin{array}{c}\text { Natural } \\
\text { education- } \\
\text { oriented } \\
\text { development }\end{array}$} & (Constant) & 2.400 & .258 & & 9.288 & .000 \\
\hline & $\begin{array}{l}\text { Positive } \\
\text { attitudes }\end{array}$ & .148 & .064 & .153 & 2.314 & $.022^{*}$ \\
\hline & \begin{tabular}{|l} 
Active \\
attitudes
\end{tabular} & .317 & .060 & .353 & 5.289 & $.000^{*}$ \\
\hline & $\begin{array}{l}\text { Negative } \\
\text { attitudes }\end{array}$ & -.114 & .049 & -.136 & -2.349 & $.020^{*}$ \\
\hline & \multicolumn{6}{|c|}{$R^{2}=.251, F=26.422$, Sig. $=.000$} \\
\hline \multirow{5}{*}{$\begin{array}{c}\text { Visitor- } \\
\text { oriented } \\
\text { development }\end{array}$} & (Constant) & 2.314 & .247 & & 9.372 & .000 \\
\hline & $\begin{array}{l}\text { Positive } \\
\text { attitudes }\end{array}$ & .082 & .061 & .093 & 1.333 & .184 \\
\hline & $\begin{array}{l}\text { Active } \\
\text { attitudes }\end{array}$ & .264 & .057 & .327 & 4.613 & $.000 *$ \\
\hline & $\begin{array}{l}\text { Negative } \\
\text { attitudes }\end{array}$ & -.032 & .046 & -.043 & -.697 & .486 \\
\hline & \multicolumn{6}{|c|}{$R^{2}=157, F=14.638$, Sig. $=.000$} \\
\hline
\end{tabular}

Method: Enter * $p<.05$ 
표준화계수 -.136 으로 '자연교육중심개발'에 부정적인 영향을 끼 치는 것으로 나타났다. 이는 과거 여주시 수변공간이 수도권정 비계획법상 자연보전권역으로 생태계가 잘 보존되어 있어 교 육환경에 적합하기 때문에 자연교육중심개발에 긍정적 태도를 가지는 것으로 해석할 수 있다. 마지막으로 주민태도 요인이 '방문객중심개발' 형태에 영향을 미치는지를 알아보기 위해 '긍 정적 태도', '적극적 태도', '부정적 태도'를 독립변수로 두고, '방 문객중심개발' 형태를 종속변수로 두어 다중회귀분석을 실시하 였다(Table 9 참조). 분석결과, 주민태도와 '방문객중심개발' 간의 관계는 유의수준 .05에서 '적극적 태도'에서만 영향을 주 는 것으로 나타났다. 따라서 여주시 수변공간 개발에 대한 '적 극적 태도'는 '방문객중심개발'에 긍정적인 영향을 끼친다고 해 석할 수 있다. '방문객중심개발'에 대한 태도는 '긍정적 태도'와 '부정적 태도'를 가진 주민의 외부 방문객에 대한 인식이 '적극 적 태도'의 주민에 비해 상대적으로 부족하여 위와 같은 결과가 나온 것으로 사료된다.

\section{4. 거주특성에 따른 수변공간 개발에 대한 주민태도 차이}

사회교환이론에 따라 지역개발 대상지 주민의 일반특성과 지역주민태도 간의 차이를 선행연구를 통해 살펴보면 지역주 민의 인구통계학적 특성은 거주특성에 비해 상대적으로 연관 성이 적은 것으로 밝혀지고 있다(Cho et al, 2005). 따라서 본 연구에서는 수변공간 개발에 대한 주민태도 요인분석 결과 (Table 7 참조)를 바탕으로 여주시 지역주민의 일반특성 중 거 주특성에 따른 수변공간 개발에 대한 주민태도 차이분석을 실 시하였다.

1) 고향에 따른 수변공간 개발에 대한 주민태도 차이검증 고향에 따른 수변공간 개발에 대한 주민태도 간의 차이를 알 아보기 위해 $T$-test를 수행하였다(Table 10 참조).

분석 결과, '긍정적 태도' $(t=.605)$, '적극적 태도' $(t=-.064)$, '부

Table 10. Difference verification for resident's attitudes according to home town

\begin{tabular}{|c|c|c|c|c|c|c|}
\hline & Division & Mean & $\begin{array}{l}\text { Standard } \\
\text { deviation }\end{array}$ & $t$ & $d f$ & Sig \\
\hline \multirow{2}{*}{$\begin{array}{l}\text { Positive } \\
\text { attitude }\end{array}$} & Home town & 2.85 & .882 & \multirow{2}{*}{.605} & \multirow{2}{*}{238} & \multirow{2}{*}{.546} \\
\hline & Non-home town & 2.78 & .842 & & & \\
\hline \multirow{2}{*}{$\begin{array}{l}\text { Active } \\
\text { attitude }\end{array}$} & Home town & 3.43 & .935 & \multirow{2}{*}{-.064} & \multirow{2}{*}{238} & \multirow{2}{*}{.949} \\
\hline & Non-home town & 3.44 & .934 & & & \\
\hline \multirow{2}{*}{$\begin{array}{l}\text { Negative } \\
\text { attitude }\end{array}$} & Home town & 2.55 & 1.113 & \multirow{2}{*}{-.143} & \multirow{2}{*}{235.46} & \multirow{2}{*}{.886} \\
\hline & Non-home town & 2.57 & .847 & & & \\
\hline \multirow{2}{*}{$\begin{array}{l}\text { Whole } \\
\text { attitude }\end{array}$} & Home town & 3.04 & .641 & \multirow{2}{*}{.267} & \multirow{2}{*}{238} & \multirow{2}{*}{.790} \\
\hline & Non-home town & 3.01 & .629 & & & \\
\hline
\end{tabular}

정적 태도 $(t=-.143)$ 는 유의한 차이가 없는 것으로 나타나 $(p<.05)$, 고향에 따른 수변공간 개발에 대한 주민태도 요인 간에는 차이 가 없다는 결과를 얻었다. 이를 통해 여주시 지역주민의 고향 여부는 수변공간 개발에 영향을 주지 않는 것을 확인할 수 있 었다. 이 결과는 선행연구와 동일한 결과이며, 수변공간 개발에 의한 개인의 편익이 통제되지 않았기 때문인 것으로 해석할 수 있다.

2) 여주시 거주기간에 따른 수변공간 개발에 대한 주민태도 차이검증

여주시 거주기간에 따른 수변공간 개발에 대한 주민태도 차 이를 알아보기 위해 일원분산분석(one-way ANOVA)을 수행 하였다(Table 11 참조). ANOVA 분석결과, 여주시 거주기간 에 따른 수변공간 개발에 대한 주민태도는 유의한 값을 나타내 지 않아 $(p<.05)$ 거주기간과 주민태도 요인 간에는 차이가 없다 고 나타났다. 이는 여주시가 수도권정비계획법이 제정된 1984년

Table 11. Difference Verification for resident's attitudes according to residence period

\begin{tabular}{|c|c|c|c|c|c|}
\hline \multicolumn{2}{|c|}{ Division } & Mean & $\begin{array}{l}\text { Standard } \\
\text { deviation }\end{array}$ & $F$ & $P$-value \\
\hline \multirow{6}{*}{$\begin{array}{l}\text { Positive } \\
\text { attitude }\end{array}$} & $\geq 5$ years & 2.71 & .862 & \multirow{6}{*}{.426} & \multirow{6}{*}{.830} \\
\hline & $6 \sim 10$ years & 2.92 & .770 & & \\
\hline & $11 \sim 20$ years & 2.72 & .816 & & \\
\hline & $21 \sim 30$ years & 2.88 & .908 & & \\
\hline & $31 \sim 40$ years & 2.86 & .856 & & \\
\hline & $>40$ years & 2.87 & .971 & & \\
\hline \multirow{6}{*}{$\begin{array}{l}\text { Active } \\
\text { attitude }\end{array}$} & $\geq 5$ years & 3.37 & .941 & \multirow{6}{*}{.749} & \multirow{6}{*}{.588} \\
\hline & $6 \sim 10$ years & 3.29 & .803 & & \\
\hline & $11 \sim 20$ years & 3.38 & .989 & & \\
\hline & $21 \sim 30$ years & 3.38 & .930 & & \\
\hline & $31 \sim 40$ years & 3.65 & .881 & & \\
\hline & $>40$ years & 3.57 & .993 & & \\
\hline \multirow{6}{*}{$\begin{array}{l}\text { Negative } \\
\text { attitude }\end{array}$} & $\geq 5$ years & 2.49 & .834 & \multirow{6}{*}{2.187} & \multirow{6}{*}{.056} \\
\hline & $6 \sim 10$ years & 2.48 & .713 & & \\
\hline & $11 \sim 20$ years & 2.90 & .968 & & \\
\hline & $21 \sim 30$ years & 2.63 & 1.057 & & \\
\hline & $31 \sim 40$ years & 2.40 & 1.093 & & \\
\hline & $>40$ years & 2.27 & 1.146 & & \\
\hline \multirow{6}{*}{$\begin{array}{l}\text { Whole } \\
\text { attitude }\end{array}$} & $\geq 5$ years & 2.95 & .676 & \multirow{6}{*}{.288} & \multirow{6}{*}{.919} \\
\hline & $6 \sim 10$ years & 3.00 & .587 & & \\
\hline & $11 \sim 20$ years & 3.03 & .580 & & \\
\hline & $21 \sim 30$ years & 3.05 & .680 & & \\
\hline & $31 \sim 40$ years & 3.11 & .594 & & \\
\hline & $>40$ years & 3.06 & .703 & & \\
\hline
\end{tabular}


이후부터 자연보전권역으로 개발행위에 대한 규제를 받아왔기 때문에 거주기간과 차이가 나타나지 않는다고 해석할 수 있다.

3) 거주지역에 따른 수변공간 개발에 대한 주민태도 차이검증 여주시 거주지역에 따른 수변공간 개발에 대한 주민태도 차 이를 알아보기 위해 일원분산분석(one-way ANOVA)을 수행 하였다(Table 12 참조). ANOVA 분석결과, 수변공간 개발에 대한 '부정적 태도'의 $F$ 값은 3.048, 유의확률 .029로 유의한 결 과를 나타냈다 $(p<.05)$. 구체적인 집단 간의 차이를 알아보기 위해 Duncan 사후검증을 실시하였고, 사후검증 결과, 가남·대 신지역생활권과 북내지역생활권 간에 차이가 있는 것으로 분 석되었다. 여주시는 수변공간 인근에 거주지역이 밀집해 있으 며, 과거 잦은 홍수 피해를 입었던 지역이기 때문에 '부정적 태 도'에서 차이가 발생한 것으로 해석할 수 있다.

4) 부동산 소유 여부에 따른 수변공간 개발에 대한 주민태도 차이검증

부동산 소유 여부에 따른 수변공간 개발에 대한 주민태도 차 이검증을 하기 위해 독립 T-test를 수행하였다(Table 13 참조). 분석 결과 '긍정적 태도' $(t=1.453)$, '적극적 태도' $(t=.834)$, '부정 적 태도' $(t=-.838)$ 는 유의한 차이가 없는 것으로 나타나 $(p<.05)$ 부동산 소유 여부에 따른 주민태도 요인은 차이가 없다는 것을 확인하였다. 이러한 결과는 부동산 소유의 형태가 대부분 주택 이나 논의 형태이며, 수변공간 개발가능 공간과는 거리가 있기

Table 12. Difference verification for resident's attitudes according to residence districts

\begin{tabular}{|c|c|c|c|c|c|c|}
\hline & Division & Mean & $\begin{array}{l}\text { Standard } \\
\text { deviation }\end{array}$ & Duncan & $F$ & $P$-value \\
\hline \multirow{4}{*}{$\begin{array}{l}\text { Positive } \\
\text { attitude }\end{array}$} & Yeoju central district & 2.78 & .803 & - & \multirow{4}{*}{1.542} & \multirow{4}{*}{.204} \\
\hline & Daeshin district & 2.81 & .727 & - & & \\
\hline & Buknae district & 3.18 & 1.244 & - & & \\
\hline & Ganam district & 2.71 & 1.050 & - & & \\
\hline \multirow{4}{*}{$\begin{array}{l}\text { Active } \\
\text { attitude }\end{array}$} & Yeoju central district & 3.50 & .925 & - & \multirow{4}{*}{1.427} & \multirow{4}{*}{.236} \\
\hline & Daeshin district & 3.25 & .802 & - & & \\
\hline & Buknae district & 3.65 & 1.155 & - & & \\
\hline & Ganam district & 3.37 & 1.036 & - & & \\
\hline \multirow{4}{*}{$\begin{array}{l}\text { Negative } \\
\text { attitude }\end{array}$} & Yeoju central district & 2.52 & 1.040 & $a b$ & \multirow{4}{*}{3.048} & \multirow{4}{*}{$.029 *$} \\
\hline & Daeshin district & 2.65 & .823 & $\mathrm{~b}$ & & \\
\hline & Buknae district & 2.11 & .963 & $\mathrm{a}$ & & \\
\hline & Ganam district & 2.96 & 1.073 & $b$ & & \\
\hline \multirow{4}{*}{$\begin{array}{l}\text { Whole } \\
\text { attitude }\end{array}$} & Yeoju central district & 3.03 & .618 & - & \multirow{4}{*}{.720} & \multirow{4}{*}{.541} \\
\hline & Daeshin district & 2.97 & .528 & - & & \\
\hline & Buknae district & 3.20 & .891 & - & & \\
\hline & Ganam district & 3.02 & .710 & - & & \\
\hline
\end{tabular}

Table 13. Difference verification for resident's attitudes according to ownership of real estate

\begin{tabular}{|c|c|c|c|c|c|c|}
\hline \multicolumn{2}{|c|}{ Division } & Mean & $\begin{array}{l}\text { Standard } \\
\text { deviation }\end{array}$ & t & $d f$ & Sig \\
\hline \multirow{2}{*}{$\begin{array}{l}\text { Positive } \\
\text { attitude }\end{array}$} & Owner & 2.89 & .796 & \multirow{2}{*}{1.453} & \multirow{2}{*}{238} & \multirow{2}{*}{.148} \\
\hline & Non-owner & 2.73 & .929 & & & \\
\hline \multirow{2}{*}{$\begin{array}{l}\text { Active } \\
\text { attitude }\end{array}$} & Owner & 3.48 & .881 & \multirow{2}{*}{.834} & \multirow{2}{*}{238} & \multirow{2}{*}{.405} \\
\hline & Non-owner & 3.38 & .990 & & & \\
\hline \multirow{2}{*}{$\begin{array}{l}\text { Negative } \\
\text { attitude }\end{array}$} & Owner & 2.51 & .939 & \multirow{2}{*}{-.838} & \multirow{2}{*}{238} & \multirow{2}{*}{.403} \\
\hline & Non-owner & 2.62 & 1.063 & & & \\
\hline \multirow{2}{*}{$\begin{array}{l}\text { Whole } \\
\text { attitude }\end{array}$} & Owner & 3.07 & .608 & \multirow{2}{*}{1.112} & \multirow{2}{*}{238} & \multirow{2}{*}{.267} \\
\hline & Non-owner & 2.98 & .664 & & & \\
\hline
\end{tabular}

때문에 나타난 것으로 사료된다.

\section{V. 결론}

최근 몇 년 동안 수변공간을 대상으로 지속가능한 지역균형 발전을 목표로 하는 지역개발 정책 및 사업이 급격히 증가하였 다. 이러한 개발 활동으로 발생하는 경제·사회·문화적 파급 효과에 대한 기대가 증가하고 있지만, 다른 한편으로는 외부방 문객 증가로 인한 지역사회 충돌 및 생활환경 변화에 대한 지 역문제를 겪게 되기도 한다(Ahn et al., 2002). 이에 대한 해결 방안으로 지역 주민의 개발에 대한 태도를 통해 지역의 환경 및 사회적 변화의 허용한계를 검토해야 할 필요성이 제기되었 다. 지역주민의 개발에 대한 허용한계는 LAC 시스템을 통해 예측 가능하다. $\mathrm{LAC}$ 는 지역개발계획에서 지속가능성의 개념 을 적용하기 위한 모범적인 모델로, 4 가지의 결정과정과 실무 에서 적용 가능한 9 단계로 나뉘어 활용되고 있다. 특히 LAC 1 단계는 지역주민의 태도와 의견이 반영되는 첫 번째 단계로, 지역의 개발 목적 확립을 위한 핵심 단계이며, 후속단계의 연 구들에도 큰 영향을 미치기 때문에 신중하게 평가되어야 한다. 이에 본 연구에서는 새로 조성된 수변공간의 허용 가능한 개발 형태 분석 및 향후 개발의 목표를 설정해 주기 위해 지역주민 의 거주특성, 주민태도, 수변공간 개발에 대한 허용 가능한 형 태를 측정 변수로 하여 LAC 1단계 분석을 실시하였다. 분석과 정은 먼저 지역주민의 어떠한 태도가 허용 가능한 형태에 영향 을 미치는지를 파악하였으며, 다음으로 지역주민의 거주특성에 따라 수변공간 개발에 대한 태도에 차이가 있는지에 대해 검증 하였다.

$\mathrm{LAC} 1$ 단계를 수행하기 위해 본 연구에서 개발에 대한 주민 태도가 '긍정적 태도'를 가지고 있으면 개발에 긍정적인 영향을 주며, '부정적 태도'를 가지고 있으면 부정적 영향을 끼친다는 사회교환이론에 따라 지역주민의 긍정적인 태도는 지속가능한 
수변공간 개발을 하는데 중요한 역할을 한다는 것을 전제로 하 였다. 여주시 수변공간의 허용 가능한 개발 형태를 선정하기 위해 수변공간 개발에 대한 주민태도와 허용 가능한 수변공간 개발 형태 간의 관계를 알아본 결과, '긍정적 태도'는 '자연교육 중심 개발에서 유의한 영향을 미쳤으며, '적극적 태도'는 '활동 중심개발', '자연교육중심개발', '방문객중심개발'의 형태에서 모 두 유의한 것으로 나타났다. 이에 '적극적 태도'는 수변공간의 허용 가능한 개발 형태에 대한 목표를 설정하기에 무리가 있다 고 판단하였다. '부정적 태도'는 '활동중심개발', '자연교육중심 개발'에서 유의하지만, 부정적 영향을 주는 것으로 나타났다.

연구결과를 바탕으로 LAC 후속단계 연구 수행을 위해 최종 적으로 '자연교육중심개발'을 여주시 허용 가능한 수변공간 개 발 형태로 지정하여 수변공간 개발에 대한 구체적 목표를 설정 하였다. 첫째, 여주군 지역주민의 거주지역을 고려하여 개발지 역을 선정해야 한다. 수변공간에 ‘긍정적 태도'를 가진 지역주 민의 태도는 수변공간 개발에 긍정적 영향을 줄 수 있을 것이 다. 둘째, 여주군 지역주민 참여를 통해 방문객들에게 여주군 수변공간의 개발되지 않은 자연환경을 볼 수 있는 장소를 제공 해야 한다. 외부 방문객의 경우 '자연교육중심개발' 참여에 있 어 어린이를 동반한 형태가 많을 것으로 예상되기 때문에, 이 를 고려한 공간도 마련되어야 할 것이다. 셋째, '자연교육중심 개발을 위한 인프라 정비 및 프로그램을 개발해야 한다. 관련 요소로는 관광명소로의 양호한 접근 제공, 오염 정화시설 설치, 개발되지 않은 자연환경을 볼 수 있는 장소제공, 야생생물을 관찰할 수 있는 장소의 제공 등이 있다. 넷째, 지역주민들의 커 뮤니티 활동 지원, 자연환경 교육 시설 개발, 생태 해설가 양성 과 같은 교육 및 프로그램이 지원되어야 할 것이다. 마지막으 로 위 목표에 대한 가능성을 분석하고, 지역별 현재조건 및 향 후변화 전망을 측정하여 관리하고자 하는 자원과 사회적 조건 을 제시해야 할 것이다.

다음으로 거주지역에 따른 수변공간 개발에 대한 주민태도 의 차이검증을 실시한 결과, 거주특성 중 고향 여부, 거주기간, 부동산 소유 여부와 수변공간 개발에 대한 주민태도 요인 간에 유의한 값이 나타나지 않았다. 반면, 거주특성 중 거주지역과 수변공간 개발에 대한 주민태도 요인은 '부정적 태도' 요인에서 유의한 값이 나타났다. 이는 LAC 시스템 2단계의 휴양자원 등 급화 과정에서 지역주민의 거주지역을 고려하여 등급화해야 할 것이다. 즉, 휴양자원 등급화 과정에서 개발에 대한 부정적 태도에 차이를 나타낸 대신 · 가남지역생활권과 북내지역생활 권에 대한 특성을 반영하여 가중치 등을 부여해야 할 것으로 사료된다.

본 연구에서는 지역주민의 태도를 고려한 허용 가능한 수변 공간 개발 형태 및 목적을 도출함으로써 LAC의 후속단계에서 지역의 현황과의 관계 분석의 기준을 마련하였다. 또한 지역주
민의 거주특성과 수변공간 개발에 대한 태도 차이분석을 통해 휴양자원 등급화 단계가 가지고 있던 대상지의 적용범위의 한 계에 대한 고찰을 하였다는 점에서 의의가 있다. 이는 향후 $\mathrm{LAC}$ 시스템 2단계인 휴양자원 등급화 과정에서 보다 명확한 등급 설정을 기대할 수 있다.

이와 같이 지역주민 태도를 고려한 LAC 시스템 연구는 지 역주민과 방문객 간의 갈등요소 완화, 지역주민 간에는 유대관 계를 증대시킬 수 있으며, 장기적으로는 지역 활성화 및 경제 발전에 기여할 수 있을 것으로 사료된다. 본 연구의 한계는 주 민특성에 따른 수변공간 개발에 대한 주민태도를 분석함에 있 어 지역사회의 경제적 여건 및 개발에 의한 구체적인 개인적 편익에 대한 고찰이 부족했다는 점이다. 또한, 대상지 선정에 있어 여주시의 수변공간 범위가 너무 광범위한 점을 들 수 있 다. 향후 연구에서는 개발에 의한 지역주민의 경제성을 충분히 고려하고, 휴양자원 등급별 비교분석이 수행되어야 할 것이다.

\section{인용문헌}

1. Ahn, B. Y., B. K. Lee and C. S. Shafer(2002) Operationalizing sustainability in regional tourism planning: An application of the limits of acceptable change framework. Tourism Management 23(1): 1-15.

2. Ajzen, L.(1988) Attitudes, Personality, and Behavior. Chicago: The Dorsey Press.

3. Allen, L. R., H. R. Hafer, P. T. Lon and R. R. Perdue(1993) Rural residents' attitudes toward recreation and tourism development. Journal of Travel Research 31(4): 27-33.

4. Andereck, K. L. and C. A. Vogt(2000) The relationship residents' attitudes toward tourism and tourism development options. Journal of Travel Research 39(1): 27-36.

5. Ap, J.(1992) Residents' perceptions on tourism impacts. Annals of Tourism Research 19(4): 665-690.

6. Baek, S. M. and E. I. Noh(2006) Development of Waterfront as Leisure Space. Seoul: Seoul Development Institute.

7. Belisle, F. J. and D. R. Hoy (1992) The perceived impact of tourism by residents a case study in Santa Marta, Colombia. Annals of Tourism Research 7: 83-101.

8. Cho, B. H., Y. H. Choi and D. H. Kim(2005) Residents perception differences on tourism impacts. Journal of the Korean Association of Regional Geographers 11(5): 426-439.

9. Cho, K. I. and N. J. Kim(2002) Structural equation analysis of resident attitudes to tourism development. Journal of Tourism Sciences 26(2): 31-51.

10. Cho, S. W. and D. H. Song(2012) Application of the planning factors on urban waterfront for composition of the landscape characteristics With special emphasis on the urban waterfront development of the domestic and overseas cases. Journal of The Urban Design Institute of Korea 13(6) : 103-117.

11. Choi, S. M. and N. J. Kim(2005) Attitudes of tourism-involved civil servants towards tourism development. Journal of Tourism Sciences 29(1): 209-227.

12. Choi, Y. G. (2000) Concept and project for sustainable tourism. Planning and Policy 223: 6-19.

13. Choi, Y. H. and H, Lee(2006) Perceptions and cluster characteristics of residents based on distance effects and social representation theory: Public show-caves. Journal of Tourism Sciences 30(2) : 161-180. 
14. Diedrich, A., P. B. Huguet and J. T. Subirana(2011) Methodology for applying the limits of acceptable change process to the management of recreational boating in the Balearic Islands, Spain(Western Mediterranean). Ocean and Coastal Management 54(4): 341-351.

15. Frissel, S. S. and G. H. Stankey(1972) Wilderness environmental quality: Search for social and ecological harmony. Proceeding of the Society of American Foresters Annual Conference, Washington, D.C..

16. Huh, H. J., Y. H. Hyun and S. C. Huh(2005) The structural equation modeling approach to the relationships between the residents' attitude towards participation, status of local economy, and the type of tourism development based on social exchange theory. Journal of Tourism Sciences 29(3): 229-250.

17. Jang, J. H. (2012) A study on differences of residents' attitudes toward tourism development impacts - Focused on nearby residents and faroff residents. Journal of Tourism Sciences 27(3): 337-355.

18. Jang, S. H., J. Y. Yoon, S. D. Kim and Y. N. Yoon(2007) An establishment of operation and management system for flood control and conservation in reservoir with gate : II. Establishment of efficient reservoir management and operation system. Journal of the Korean Society of Civil Engineers 27(2): 141-150.

19. Jeong, J. E., D. W. Ko and J. T. Yeo(2007) An application of the limits of acceptable change for sustainable regional tourism development based upon residents' attitudes by recreation opportunity spectrum. Journal of Tourism Sciences 31(3): 289-310.

20. Jeong, J. U.(2005) The Model of Sustainable Tourism Development by Regional ROS Characteries. Ph. D. Dissertation. Kyonggi University, Suwon.

21. Kaltenborn, B. P., O. Andersen, C. Nellemann, T. Bjerke and C. Thrane (2008) Resident attitudes towards mountain second-home tourism development in Norway: The effects of environmental attitudes. Journal of Sustainable Tourism 16(6): 664-680.

22. Kang, S. K. (2002) Residents' attitudes toward tourism development Case study from Andong Hahoe Village -. Journal of Korean Association For Cultural Economics 5(1): 139-158.

23. Kim, D. W.(2009) A Study of Plans to Make Livable Communities by Improving Space Quality : With Local Residents and Users. Master Dissertation. Seoul National University, Seoul.

24. Kim, E. K. (2004) Residents' perceptions toward tourism development : The case of Jungmun and Sungsanpo tourist complex. Journal of Foodservice Management 7(1): 123-138.

25. Kim, H. C., H. W. Lee and K. H. Ahn(2013) Planning characteristics and spatial strategies of abroad waterfront developments by scale types of regional, urban, and local levels - Focusing on clyde waterfront, Hafen city, Battery park city -. Journal of Korean Institute of Urban Design 14(2): 81-98

26. Kim, J. S.(2003) Evaluation of wetland as application on limits of acceptable change : LAC, recreation opportunity spectrum : ROS methods. Journal of Korean Institute of Landscape Architecture 31(4): 57-66.

27. Kim, K. S.(2007) Legal aspects of reshaping Seoul metropolitan land planning - Land planning and globalization. Public Land Law Review $37(2): 22-49$.

28. Kim, K. S.(2011) An approach of design development method for urban waterfront space of leisure culture infrastructure. Journal of Digital Design 11(3): 121-129.

29. Ko, D. W. and J. E. Jeong(2007) The differences of attitudes toward tourism development by regional ROS characteristics as a approaches methodology of LAC for sustainable regional tourism development. Tourism Study 22(1): 529-548.

30. Kwon, Y. S. and M. S. Cho(2010) A study on the urban planning and design principles on Riverfront. Report to Architecture Urban Research Institute.

31. Kwon, Y. S. and M. S. Cho(2011) The character of urban design around the riverfront area in Korea - Focused on the composition of public space and land use pattern. Journal of the Architectural Institute of Korea Planning and Design 27(9): 251-260

32. Látková, P. and C. A. Vogt(2012) Residents' attitudes toward existing and future tourism development in rural communities. Journal of Travel Research 51(1): 50-67.

33. Lee, B. H.(2009) Utilization of water-friendly space for rural-urban exchange and rural tourism. Korea Irrigation and Drainage 11(2): 199-205.

34. Lee, D. G., G. J. Bang, I. S. Kim, S. W. Yun, H. G. Kang and J. Y. Kim(1999) The foundation research development of Anmyundo based on a consciousness of resident and visitor. The Korea Society of Environmental Restoration Technology 2(4): 35-46,

35. Lee, H. J.(2004) Study on the Rural People's Attitude toward Leisure : Focused on Incheon Metropolitan City. Master Dissertation. Incheon National University, Incheon.

36. Lee, H. K., H. W. Jun and J. A. Kim(2012) Socio-economic and environmental effects of waterfront development on the civic resistance : Centering around inhabitants alongside the Nakdong river. Journal of Tourism Sciences 27(2): 435-454.

37. Lee, S. J. and S. H. Heo(2012) Strategies for river-based leisure in Gyeonggi-do. Research Report to Gyeonggi Research Institute.

38. Lim, S. B. (1998) Landscape Urbanism. Seoul: Seoul National University Press.

39. Lime, D. W.(1970) Research for determining use capacities of the boundary waters canoe area, naturalist. Journal of Travel Research $21(4): 8-13$.

40. Madrigal, R.(1993) A tale of tourism in two cities. Annals of Tourism Research 20(2): 336-353.

41. Mansfeld, Y.(1992) Group-differentiated perceptions of social impacts related to tourism development. Professional Geographer 44: 377-392.

42. Mbaiwa, J. E. and A. L. Stronza(2011) Changes in resident attitudes towards tourism development and conservation in the Okavango Delta, Botswana. Journal of Environmental Management 92(8): 1950-1959.

43. McCool, S. F.(1994) Planning for sustainable nature dependent tourism development: The limits of acceptable change system Tourism Recreation Research 19(2): 51-55.

44. Ministry of Culture Sports and Tourism(2011) Waterfront cultural tourism development plan. Research Report to Ministry of Culture Sports and Tourism.

45. Ministry of Land(2007) Present Status of Ecological Space in Waterfronts.

46. Oh, J. H. and Y. S. Yoon(2009) Impact of place attachment, priority, evaluation, satisfaction toward tourism development and demographic attributes of residents on support, cognition of effectiveness of tourism development - The case of Kangwon province -. Tourism Study 24(5): 275-295.

47. Oh, S. H.(2010) A Study on the Planning Method for Typology of River Amenity Improvement. Master Dissertation. Kyungwon University, Seongnam.

48. Oh, S. H., E. J. Oh and C. Jung(2012) Development of impact management model for small islands tourists. -Apply SIEOS Udo of Jeju-. Proceeding of The 71th TOSOK International Tourism Conference. Seoul: The Tourism Sciences Society of Korea. pp. 1201-1218.

49. Park, C. K. and H. Y. Kim(2011) The influence on residents recognition and attitude on their farm village development in a comprehensive rural village development project. Journal of The 
Economic Geographical Society of Korea 14(3): 419-436.

50. Perdue, R. R., P. T. Long and Y. S. Kang(1995) Resident support for gambling as a tourism development strategy. Journal of Travel Research 34(2): 3-11.

51. Rural Development Administration(2012) Waterfront Design Guidelines in Rural Communities. Suwon: Rural Development Administration, National Academy of Agricultural Science.

52. Saveriades, A.(2000) Establishing the social tourism carrying capacity for the tourist resorts of the east coast of the republic of Cyprus. Tourism Management 21(2): 147-156.

53. Sheldon, P. J. and T. Abenoja(2001) Residents attitudes in a mature destination -The case of Wikiki-. Tourism Management 22: 435-443,

54. Shim, W. K. and K. J. Baek(2000) Development of the close - to nature construction technology for the low - flow revetment of the stream - A case of Jungpyung stream in Yongin City -. Journal of Korean Institute of Landscape Architecture 28(1): 83-91.

55. Shin, S. H. and H. J. Yoon(2011) Research paper : Re-visitation choice impacts of consideration on sustainable tourism development -Using logit and probit models-. Korean Society of Rural Planning 17(1): 59-65.

56. Song, K. I., J. J. Kim and Y. J. Kim(2010) Study on factors influencing leisure \& tourism space and attitude of local community. Tourism Study 24(6): 473-493.

57. Stankey, G. H., D. N. Cole, R. C. Lucas, M. E. Petersen and S. S.
Frissell (1985) The Limits of Acceptable Change(LAC) System for Wilderness Planning. United States: Department of Agriculture Forest Service. 58. Teye, V., S. F. Sönmez and E. Sirakaya(2002) Residents' attitudes toward tourism development. Annals of Tourism Research 29(3): 668-688.

59. Vargas-Sánchez, A., N. Porras-Bueno and M. D. L. Á Plaza-Mej̆a (2011) Explaining residents' attitudes to tourism: Is a universal model possible? Annals of Tourism Research 38(2): 460-480.

60. Yeoju-Gun(2007) 2020 Yeoju Master Plan. Research Report to YeojuGun.

61. Yeoju-Gun(2011) Social Statistics Survey in Yeoju-gun. Research Report to Yeoju-Gun

62. Yoo, K. J., B. H. Han, J. W. Choi and J. Y. Heo(2012) A study on community member perception due to impacts on development of the Dulegil in Bukhansan National Park. The Korea Society of Environment and Ecology 26(1): 113-124.

63. Zamani-Farahani, H. and G. Musa(2008) Residents' attitudes and perception towards tourism development: A case study of Masooleh, Iran. Tourism Management 29(6) : 1233-1236.

64. 畔柳昭雄 and 渡邊秀俊(1999）都市の水邊と人間行動：都市生態學的視 点による親水行動論. Kim, N. Y. and H. S. Lee(translation) Urban Waterfronts and Human Behavior. Seoul: Sunin, 2011. 